\title{
PENGARUH STRATEGI PEMBELAJARAN ACTIVE KNOWLEDGE SHARING TERHADAP MOTIVASI BELAJAR MATA KULIAH MASA'ILUL FIQHIYAH MAHASISWA STAI ALHIKMAH JAKARTA
}

\author{
Viika Amalia Ainuna Wati dan Taufik Abdillah Syukur \\ SMP Negeri 17 Tanggerang Selatan, UIN Syarif Hidayatullah \\ Jakarta \\ ainunaviika@gmail.com, taufik.a@uinjkt.ac.id
}

\section{Abstract}

This study aims to find out the influence of learning strategies active knowledge sharing on learning motivation masa'ilul fiqhiyah courses students of Islamic High School ALHIKMAH Jakarta. The method used through a quantitative approach and using a simple regression statistical test. The results of the study showed that there was a significant effect between active knowledge sharing learning strategies on learning motivation at the masa'ilul fiqhiyah. This is evidenced by the acquisition of $r$ count $>r$ table $(0.871>0.361)$ which means $\mathrm{Ha}$ is accepted and Ho is rejected. And the magnitude of the effect of active knowledge sharing learning strategies on learning motivation was $75,8 \%$, while $24,2 \%$ of learning motivation was influenced by other variables not examined.

Keywords: Strategies Active Knowledge Sharing; Motivation; Masa'ilul Fiqhiyah. 


\section{Abstrak}

Penelitian ini bertujuan untuk mengetahui adanya pengaruh strategi pembelajaran active knowledge sharing terhadap motivasi belajar matakuliah masa'ilul fiqhiyah mahasiswa STAI ALHIKMAH Jakarta. Metode yang digunakan melalui pendekatan kuantitatif dan menggunakan uji statistic regresi sederhana. Hasil penelitian menunjukkan bahwa terdapat pengaruh yang signifikan antara strategi pembelajaran active knowledge sharing terhadap motivasi belajar matakuliah masa'ilul fiqhiyah mahasiswa STAI ALHIKMAH Jakarta. Hal ini dibuktikan dengan perolehan $r$ hitung $>r$ tabel $(0,871>0,361)$ yang berarti Ha diterima dan Ho ditolak. Dan besarnya pengaruh strategi pembelajaran active knowledge sharing terhadap motivasi belajar matakuliah masa'ilul fiqhiyah mahasiswa STAI ALHIKMAH Jakarta sebesar 75,8\%, sedangkan 24,2\% motivasi belajar dipengaruhi variable lain yang tidak diteliti.

Kata kunci: Strategi Pembelajaran Active Knowledge Sharing; Motivasi Belajar; Masa'ilul Fiqhiyah. 


\section{A. PENDAHULUAN}

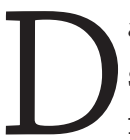
alam sebuah sistem pendidikan, sudah dipastikan terjadi sebuah proses pembelajaran. Proses pembelajaran merupakan inti dari proses pendidikan di lingkungan sekolah. Dalam hal ini, guru sebagai fasilitator atau pengajar dan siswa sebagai subjek belajarnya. Peristiwa belajar yang seperti ini akan terarah dan sistematik, karena dalam proses pembelajaran terdapat peran guru, bahan belajar, serta lingkungan yang kondusif. Menurut tokoh pendidikan Alec Bourne proses pembelajaran tidak seharusnya menggunakan gaya ceramah dan dominan "menyuapi" peserta didik. Alec berpendapat mendidik tidak hanya mentransfer pengetahuan tetapi juga mencakup proses menerima pengetahuan, mengolahnya, mendiskusikannya, dan mengatakannya kembali. Senada dengan hal ini Daniel Muijis dan David Reynold menyatakan direct instruction hasn't been effective scientifically studied until quite recently. ${ }^{1}$ Pernyataan ini memiliki arti pembelajaran langsung belum efektif sampai saat ini. Kurangnya interaksi yang biasa dilakukan selama pembelajaran menggunakan metode ceramah menjadi salah satu faktor kesulitan siswa dalam memahami materi pelajaran.

Proses pembelajaran akan berhasil manakala mahasiswa mempunyai motivasi dalam belajar. Oleh sebab itu, dosen perlu menumbuhkan motivasi belajar. Dosen harus memiliki strategi agar mahasiswa yang menguasai materi dapat membantu mahasiswa yang kesulitan dalam menguasai materi. Butuh sebuah inisiatif dari dosen untuk membentuk kelompok belajar atau kegiatan saling membagi pengetahuan sesama mahasiswa serta sebuah strategi pembelajaran dimana setiap mahasiswa mampu mengungkapkan pendapatnya dan berinisiatif untuk saling berbagi dengan mahasiswa lain dalam menyelesaikan tugas atau pertanyaan. Sehingga mahasiswa tidak hanya "disuapi" tetapi juga mencakup proses menerima pengetahuan, mengolahnya, mendiskusikannya, dan mengatakannya kembali. Solusi dari masalah ini adalah memberikan pembelajaran dimana siswa saling terlibat aktif dan

1 Daniel Muijis dn David Reynolds, Effective Teaching Evidence and Practice, (London: SAGE Publication Ltd, 2005), h. 27. 
mampu saling bekerja sama. Strategi tersebut adalah strategi pembelajaran active knowledge sharing.

Secara bahasa active knowledge sharing berarti saling tukar pengetahuan. ${ }^{2}$ Menurut Sutaryo yang dikutip dari penelitian dalam Seminar Nasional IX pendidikan biologi UNS, strategi active knowledge sharing merupakan sebuah strategi pembelajaran dengan memberikan penekanan kepada siswa untuk saling membantu menjawab pertanyaan yang tidak diketahui teman lainnya, artinya bahwa siswa yang tidak dapat menjawab pertanyaan disilahkan untuk mencari jawaban dari teman yang mengetahui jawaban tersebut dan siswa yang mengetahui jawabannya ditekankan untuk membantu teman yang kesulitan. Alasan lain memilih strategi pembelajaran active knowledge sharing karena strategi pembelajaran ini dapat membuat siswa siap belajar materi pembelajaran dengan cepat. Dengan pertanyaan-pertanyaan yang memberikan gambaran umum materi serta tanya jawab yang dilakukan antar kelompok, strategi ini memberikan kemudahan kepada siswa meskipun materi tersebut memiliki sub bab yang cukup banyak.

Strategi Pembelajaran active knowledge sharing menuntut mahasiswa untuk mampu bekerja sama memecahkan suatu permasalahan pada topic yang dibicarakan serta mengkonstruksi pengetahuan dari konsep-konsep menjadi pemahaman. Dengan demikian akan terjadi interaksi antar siswa dan guru. Karena di dalamnya siswa akan saling bertukar pengetahuan, dan guru akan membahas pendapat-pendapat yang disampaikan siswa, hal ini akan membuat suasana belajar menjadi lebih menarik dan tidak monoton. ${ }^{3}$ Dengan demikian, strategi pembelajaran active knowledge sharing merupakan salah satu cara untuk mengikat informasi yang baru kemudian menyimpannya di dalam otak, sehingga kecenderungan untuk lupa materi yang sudah diajarkan menjadi kecil.

Penelitian ini dilakukan untuk menggali informasi lebih dalam

2 Hasyim Zaini, Strategi Pembelajaran Active, (Yogyakarta: Pustaka Insan Madani, 2008), h. 22.

3 Desi Purwaningsih, Pengaruh Penggunaan Strategi Pembelajaran Active Knowledge Sharing terhadap Hasil Belajar Biologi, Ditinjau dari Gaya Belajar Siswa Kelas X SMA Negeri 5 Surakarta Tahun Pelajaran 2011/2012, Jurnal Pendidikan, Vol.3 no , September 2011, h. 94. 
tentang pengaruh strategi pembelajaran active knowledge sharing terhadap motivasi belajar mata kuliah masa'ilul fiqhiyah mahasiswa PAI di STAI ALHIKMAH Jakarta.

\section{B. KAJIAN TEORI}

\section{Motivasi Belajar}

Pengertian motif menunjukkan kepada suatu dorongan yang timbul dalam diri seseorang yang menyebabkan orang tersebut mau bertindak melakukan sesuatu. Sedangkan motivasi adalah "pendorong", suatu usaha yang disadari untuk mempengaruhi tingkah laku seseorang agar ia bergerak hatinya untuk bertindak melakukan sesuatu sehingga mencapai hasil dan tujuan tertentu. ${ }^{4}$

W.S Winkel mengartikan motivasi sebagai daya penggerak yang telah menjadi aktif. Motif menjadi aktif pada saatsaat tertentu, bila kebutuhan untuk mencapai tujuan sangat dirasakan atau dihayati. ${ }^{5}$ Sedangkan menurut Vroom, motivasi mengacu kepada suatu proses yang mempengaruhi pilihanpilihan individu terhadap bermacam-macam bentuk kegiatan yang dikehendaki. ${ }^{6}$ Menurut Mc. Donald yang dikutip oleh Sardiman A.M, motivasi adalah perubahan energy dalam diri seseorang yang ditandai dengan munculnya perasaan dan didahului dengan tanggapan terhadap adanya tujuan. ${ }^{7}$

Motivasi dalam proses pembelajaran sangat dibutuhkan dalam mencapai tujuan pembelajaran. Belajar dalam arti luas dapat diartikan sebagai suatu proses yang memungkinkan timbulnya atau berubahnya suatu tingkah laku sebagai hasil dari terbentuknya respon utama, dengan syarat bahwa perubahan atau munculnya tingkah laku baru itu bukan disebabkan oleh adanya kematangan atau oleh adanya perubahan sementara

\footnotetext{
4 M. Ngalim Purwanto, Psikologi Pendidikan, (Bandung: Remaja Rosdakarya, 1998), h. 71.

5 W.S Winnkel, Psikologi Pendidikan dan Evaluasi Belajar, (Jakarta: PT. Gramedia, 1983), h. 27.

6 M. Ngalim Purwanto, Op.cit, h. 72

7 Sardiman A.M, Interaksi dan Motivasi Belajar Mengajar, (Jakarta: Raja Grafindo Persada, 2007), h. 73 .
} 
oleh suatu hal. ${ }^{8}$

Syaiful Bahri Djamarah mengemukakan bahwa "belajar adalah suatu aktivitas yang dilakukan secara sadar untuk mendapatkan sejumlah kesan dari bahan yang telah dipelajari”. ${ }^{9}$ Belajar merupakan usaha yang dilakukan secara sadar untuk mendapat pengetahuan dari bahan yang dipelajari dan adanya perubahan dalam diri seseorang baik itu pengetahuan, keterampilan, maupun sikap dan tingkah lakunya.

Dalam sudut pandang agama Islam, motivasi belajar dapat ditumbuhkan dengan kesadaran bahwa Allah memberikan apresiasi kepada orang-orang yang memiliki ilmu pengetahuan di atas orang lain yang tidak memiliki ilmu pengetahuan. Atau orang yang memiliki pengetahuan lebih banyak, lebih ditinggikan derajatnya dari orang yang sedikit pengetahuannya. Allah SWT menjelaskan dengan firman-Nya pada surat AlMujadalah (58) ayat 11.

Berdasarkan beberapa definisi di atas dapat penulis rangkum bahwa motivasi belajar adalah keseluruhan daya penggerak dalam diri siswa yang menimbulkan kegiatan belajar, yang menjamin kelangsungan dari kegiatan belajar dan memberikan arah pada kegiatan belajar, sehingga tujuan yang dikehendaki oleh subjek belajar itu dapat tercapai. Dan beberapa aspek yang terlihat jika seseorang memiliki motivasi belajar yaitu adanya ketekunan, keuletan, dan minat dalam belajar, selalu mandiri dalam belajarnya, serta memiliki prestasi yang baik dalam pelajaran tersebut.

\section{Masailul Fiqhiyah}

Kata Masa'ilul Fiqhiyah secara etimologi berasal dari bahasa Arab yang merupakan rangkaian dari dua lafazh, yakni masa'il dan fiqhiyah. Lafazh masa'il adalah bentuk dari jama' taksir dari mas'alah yang bermakna masalah atau problem. Kata dasarnya adalah sa'ala dan bermakna "bertanya". Masail adalah masalah-

8 S. Nasution, Didaktif Asas-asas Mengajar, (Bandung : Jemmars, 1986), h. 3.

9 Syaiful Bahri Djamarah, Strategi Belajar Mengajar, (Jakarta : Rineka Cipta, 2002), h. 21. 
masalah baru yang muncul akibat pertanyaan-pertanyaan untuk dicari jawabannya. Dan fiqhiyah tidak jauh beda dari fiqih. Fiqih menurut bahasa bermakna Tahu dan faham. Menurut istilah ialah ilmu syari'at. Para fuqaha (jumhur mutaakhirin) mendefinisikan fiqh dengan "Ilmu yang menerangkan hukumhukum syara' yang diperbolehkan dari dalil-dalil yang tafshil”. ${ }^{10}$

Didalam kitab Durrul Mukhtar diterangkan bahwa fiqih mempunyai dua makna : makna ahli ushul dan makna ahli fiqih. Fiqih menurut ahli ushul ialah mengetahui hukum dari dalilnya. Sedangkan menurut ahli fiqih (fuqaha) ialah mengetahui hukum-hukum yang syara' yang menjadi sifat bagi perbuatan para hamba (mukallaf) yaitu: wajib, sunnah, haram, makruh, dan mubah. ${ }^{11}$ Jadi, masa'ilul fiqhiyah menurut pengertian bahasa adalah permasalahan-permasalahan baru yang bertalian dengan masalah-masalah atau jenis-jenis hukum (fiqh) dan dicari jawabannya.

Berdasarkan definisi secara kebahasaan di atas, maka secara istilah, masa'ilul fiqhiyah adalah problem-problem hukum Islam baru al-waqi'iyyah (faktual) dan dipertanyakan oleh umat jawaban hukumnya karena secara eksplisit permasalah tersebut tidak tertuang di dalam sumber-sumber hukum Islam. Ia juga berarti persoalan hukum Islam yang selalu dihadapi oleh umat Islam sehingga mereka beraktivitas dalam sehari-hari selalu bersikap dan berperilaku sesuai dengan tuntunan Islam.

Berdasarkan beberapa pengertian di atas, maka penulis dapat memahami bahwa masa'ilul fiqhiyah merupakan masalahmasalah baru yang muncul setelah turunnya al-Qur'an dan hadits dan setelah wafatnya Rasulullah Saw yang belum ada ketentuan hukum secara pasti, sehingga dalam mencari jawabannya memerlukan kesepakatan para ulama dalam menentukan hukum yang diambil dari al-Qur'an, Hadits, Ijma', qiyas.

10 Teungku Muhammad Hasbi Ash-Shiddieqy, Pengantar Ilmu Fiqih, (Semarang: PT. Pustaka Rizki Putra, 1999), Edisi Kedua, h.15.

11 Teungku Muhammad Hasbi Ash-Shiddieqy, op.cit, h.16. 
Masail fiqhiyyah disebut juga masail fiqhiyyah al-haditsah (persoalan hukum Islam yang baru), atau masail fiqhiyyah alashriyyah (persoalan hukum Islam kontemporer). ${ }^{12}$ Pembahasan Masailul fiqhiyah harus dilaksankan secara jelas agar mudah difahami. Peserta didik juga seharusnya focus terhadap pokok bahasan. Biasanya memang fokusnya peserta didik dipengaruhi dari motivasi masing-masing individu terhadap mata kuliah yang sedang diikuti.

\section{Strategi Pembelajaran Active Knowledge Sharing}

Menurut Reber dalam Muhibbin Syah secara harfiah, kata strategi dapat diartikan sebagai seni (art), melakasanakan, stragem yakni siasat atau rencana. Dalam perspektif psikologi, kata strategi yang berasal dari bahasa Yunani itu berarti rencana tindakan yang terdiri atas seperangkat langkah-langkah untuk memecahkan masalah atau mencapai tujuan. ${ }^{13}$ Mintzberg dan Waters yang dikutip oleh Abdul Majib mengemukakan bahwa "strategis are realized as pattern in stream of decision or action" yang memiliki arti bahwa strategi adalah pola umum tentang keputusan atau tindakan. ${ }^{14}$ Berdasarkan beberapa pengertian terkait strategi, dapat penulis ketahui, strategi adalah suatu usaha atau rencana tindakan yang terdiri dari pola-pola umum kegiatan belajar mengajar untuk mencapai tujuan pembelajaran.

Sedangkan definisi pembelajaran menurut Smith R.M. yang dikutip oleh Anisah berpendapat bahwa definisinya tidak bisa diartikan secara tepat karena istilah itu digunakan dalam berbagai hal. Jika pembelajaran digunakan untuk menyatakan hasil, maka letak penekanannya pada hasil pengalaman. Jika pembelajaran digunakan untuk menyatakan proses, biasanya proses itu untuk memenuhi kebutuhan mencapai tujuan pembelajaran. ${ }^{15}$

12 Abdurrohman Kasdi, Masail Fiqhiyyah, ( Kudus : Nora Media Enterprise,2011), h..5-6.

13 Muhibbin Syah, Psikologi Pendidikan dengan Pendekatan Baru, (Bandung: Rosdakarya, 2008), Cet ke-14, h. 210.

14 Abdul Majib, Strategi Pembelajaran, (Bandung: Remaja Rosdakarya, 2013), h. 3.

15 Anisah Basleman dan Syamsu Mappa, Teori Belajar Orang Dewasa, (Bandung : Remaja Rosdakarya, 2011), Cet ke-1, h.12-13. 
Pembelajaran aktif melibatkan siswa untuk melakukan sesuatu dan berfikir tentang sesuatu yang sedang mereka lakukan. Pembelajaran aktif terjadi ketika siswa bersemangat, siap secara mental, dan bisa memahami pengalaman yang dialami. Siswa dikatakan belajar secara aktif ketika mereka secara terus menerus terlibat, baik secara mental ataupun secara fisik. ${ }^{16}$ Strategi pembelajaran active knowledge sharing adalah salah satu strategi yang termasuk ke dalam active learning dimana pada dasarnya tujuan dan inti pembelajarannya adalah active learning. Sedangkan yang membedakan dengan strategi lain adalah langkah pelaksanaan strategi itu sendiri.

Menurut Oxford Student's Dictionary of English kata knowledge mengandung arti "the information, understanding, and skills that you gain through education or experience" ${ }^{17}$ Pernyataan tersebut mengartikan bahwa pengetahuan sebagai informasi pemahaman dan ketrampilan yang anda peroleh melalui pendidikan atau pengalaman. Kata share mengandung pengertian "to devide between two or more people". Pernyataan ini mengartikan bahwa berbagi adalah membagi antara dua orang atau lebih. Menurut Sutaryo yang dikutip oleh Asri dalam jurnalnya mengatakan bahwa strategi active knowledge sharing atau sering disebut dengan strategi saling tukar pengetahuan adalah strategi yang memberikan penekanan kepada siswa untuk saling berbagi dan membantu dalam menyelesaikan pertanyaan yang diberikan. Artinya ketika siswa yang tidak mampu menjawab suatu pertanyaan atau mengalami kesulitan, maka siswa lain yang mampu menjawab pertanyaan dapat membantu temannya. ${ }^{18}$

Menurut Nafía Dewi dalam jurnalnya mengatakan bahwa strategi pembelajaran active knowledge sharing melibatkan

16 Pat Hollingsworth dan Gina Lewis, Pembelajaran Aktif: Meningkatkan Keasyikan Kegiatan di Kelas, (Jakarta : Indeks, 2008), h. viii.

17 Oxford Fajar Sdn. Bhd, Oxford Student's Dictionary of English, (Malaysia : Fajar Bakti Sdn. Bhd, 2007), h. 308.

18 Asri Nafi'a Dewi, "Pengaruh Penggunaan Model Active Knowledge Sharing terhadap Hasil Belajar Ditinjau dari Minat Belajar Siswa SMA N 2 Karanganyar,"Penelitian disampaikan pada Seminar Nasional IX Pendidikan Biologi, FKIP Universitas Sebelas Maret, Surakarta, h. 31. 
siswa secara aktif, dimana mereka dalam kelompoknya dapat berdiskusi, dan mengaplikasikan pemahaman yang telah diperolehnya sedangkan guru lebih bertindak sebagai fasilitator dan motivator. ${ }^{19}$ Dalam hal ini tentunya seorang murid akan dituntut untuk berfikir tingkat tinggi dimana mereka harus mampu memikirkan kebenaran dan keterkaitan pemahaman yang mereka temukan secara kelompok melalui pendapatpendapat yang berbeda sehingga menjadi pemahaman utuh yang benar. Dengan demikian dapat diketahui bahwa terdapat kesamaan manfaat antara pertukaran informasi dari table Spencer dengan berbagi pengetahuan (knowledge sharing).

Strategi pembelajaran active knowledge sharing merupakan salah satu strategi yang dapat membawa siswa untuk siap belajar materi pelajaran dengan cepat. Dengan pertanyaan-pertanyaan yang memandu serta pertanyaan yang bersifat terbuka, siswa dituntut untuk mengkontruksi pemikiran mereka sehingga mereka menemukan jawaban yang benar atas konsep yang ada dan relevan. Melalui proses berbagi pengetahuan (knowledge sharing) dapat diketahui kemampuan rata-rata siswa terhadap konsep materi yang sedang dipelajari. Hal ini tentunya sangat membantu guru dalam menekankan topik penting yang mereka belum ketahui dan relevan dengan konsep materi yang sudah mereka miliki. Strategi active knowledge sharing yang digunakan adalah metode tanya jawab. Tanya jawab yang terjadi pada strategi ini adalah tiga arah yaitu guru ke siswa, siswa ke siswa lalu siswa ke guru.

Dengan demikian dapat penulis fahami bahwa active knowledge sharing lebih menitikberatkan pada saling berbagi pengetahuan atau dikenal dengan istilah knowledge sharing. Prinsip dari berbagi pengetahuan (knowledge sharing) adalah mentransfer pengetahuan kepada orang lain. Antara seseorang yang satu dengan yang lain dapat saling bertukar pengetahuan yang berasal dari pengalaman mereka masing-masing. Berbagi pengetahuan (knowledge sharing) memungkinkan proses timbal 
balik untuk membentuk kembali dan memahami pengetahuan dalam konteks baru.

\section{METODOLOGI PENELITIAN}

Penelitian ini menggunakan pendekatan kuantitatif. Penelitian dilaksanakan di STAI ALHIKMAH Jakarta yang terletak di Jl. Jeruk Purut No.10, RT.1/RW.3, Cilandak Timur, Pasar Minggu, Kota Jakarta Selatan, Daerah Khusus Ibukota Jakarta 12560. STAI ALHIKMAH Jakarta merupakan sebuah lembaga pendidikan yang berada dibawah naungan Yayasan Al Mahbubiyah yang dipimpin oleh bapak KH. Dr. Manarul Hidayat, MA dan selaku ketua STAI ALHIKMAH Jakarta yaitu bapak Prof. Dr. H. Mundzier Suparta, MA. Penelitian dilaksanakan selama 3 bulan, yaitu mulai bulan Oktober - Desember semester ganjil (semester 7) tahun pelajaran 2018/2019.

Pada penelitian ini obyek yang akan di teliti yaitu mahasiswa PAI semester VII A angkatan 2015 STAI ALHIKMAH Jakarta. Sampel penelitian ini ditentukan sebanyak 30 orang atau seluruh mahasiswa dengan alasan karena populasinya di bawah 100 . Teknik pengambilan sampel dalam penelitian ini menggunakan teknik Nonprobability yaitu sampel jenuh atau sering disebut total sampling. Jadi sampel dalam penelitian ini adalah seluruh Mahasiswa PAI semester VII A angkatan 2015 STAI ALHIKMAH Jakarta yang berjumlah 30 orang.

\section{HASIL PENELITIAN}

Peneliti memperoleh data-data penelitian tentang pengaruh strategi pembelajaran active knowledge sharing terhadap motivasi belajar mahasiswa melalui angket yang diberikan kepada 30 mahasiswa. Angket terdiri dari 2 variabel yaitu variable $X$ dan $Y$ yang masing-masing terdapat 15 pernyataan. Berikut ini data skoring motivasi belajar dan strategi pembelajaran active knowledge sharing yang diambil secara acak tidak berdasarkan nomor absen mahasiswa. 
Setelah data-data yang masuk dalam angket lalu diolah melalui editing, maka langkah berikutnya menyajikan data tersebut dalam bentuk tabel dengan menggunakan rumus presentase jawaban.

Adapun perhitungan frekuensi dan presentase dari setiap pernyataan untuk variable strategi pembelajaran active knowledge sharing (variabel X) sebagai berikut :

\section{Tabel 1}

Strategi pembelajaran active knowledge sharing pada matakuliah masa'ilul fiqhiyah membuat saya lebih berani dalam mengemukakan pendapat

\begin{tabular}{|c|l|c|c|}
\hline No. & \multicolumn{1}{|c|}{ Alternatif Jawaban } & Frekuensi & Persentase \\
\hline 1 & a. Sangat sesuai & 12 & $40 \%$ \\
& b. Sesuai & 5 & $16,7 \%$ \\
& c. Cukup Sesuai & 7 & $23,3 \%$ \\
& d. Tidak sesuai & 6 & $20 \%$ \\
& e. Sangat tidak sesuai & 0 & $0 \%$ \\
\hline & \multicolumn{1}{|c|}{ Jumlah } & 30 & $100 \%$ \\
\hline
\end{tabular}

Dari tabel di atas dapat diketahui bahwa mahasiswa PAI STAI ALHIKMAH Jakarta sebagian besar memiliki pengalaman yang sesuai dengan pernyataan. Hal ini dibuktikan dengan perolehan presentase sebesar $40 \%$ sesuai, $16,7 \%$ sesuai, $23,3 \%$ sesuai, dan $20 \%$ tidak sesuai.

\section{Tabel 2}

\section{Saya senang menjadi presentator dan dapat menjelaskan} pembahasan pada makalah yang telah dibuat

\begin{tabular}{|c|l|c|c|}
\hline No. & \multicolumn{1}{|c|}{ Alternatif Jawaban } & Frekuensi & Persentase \\
\hline 2 & a. Sangat sesuai & 16 & $53,3 \%$ \\
& b. Sesuai & 2 & $6,7 \%$ \\
& c. Cukup Sesuai & 4 & $13,3 \%$ \\
& d. Tidak sesuai & 6 & $20 \%$ \\
& e. Sangat tidak sesuai & 2 & $6,7 \%$ \\
\hline & \multicolumn{1}{|c|}{ Jumlah } & 30 & $100 \%$ \\
\hline
\end{tabular}

Dari tabel di atas dapat diketahui bahwa mahasiswa PAI STAI 
ALHIKMAH Jakarta sebagian besar senang menjadi presentator dan dapat menjelaskan pada makalah yang telah dibuat. Hal ini dibuktikan dengan perolehan skor pada angket sebesar 53,3\% sangat sesuai, $6,7 \%$ sesuai, $13,3 \%$ cukup sesuai, $20 \%$ tidak sesuai, dan hanya $6,7 \%$ yang sangat tidak sesuai.

Tabel 3

Saya ragu dalam menjawab pertanyaan audiens saat presentasi

\begin{tabular}{|c|l|c|c|}
\hline No. & \multicolumn{1}{|c|}{ Alternatif Jawaban } & Frekuensi & Persentase \\
\hline 3 & a. Sangat sesuai & 1 & $3,3 \%$ \\
& b. Sesuai & 5 & $16,7 \%$ \\
& c. Cukup Sesuai & 9 & $30 \%$ \\
& d. Tidak sesuai & 4 & $13,3 \%$ \\
& e. Sangat tidak sesuai & 11 & $36,7 \%$ \\
\hline & \multicolumn{1}{|c|}{ Jumlah } & 30 & $100 \%$ \\
\hline
\end{tabular}

Dari tabel di atas dapat diketahui bahwa mahasiswa PAI STAI ALHIKMAH Jakarta sebagian besar mahasiswa tidak ragu dalam menjawab pertanyaan disaat presentasi. Hal ini dibuktikan dengan perolehan skor $36,7 \%$ sangat tidak sesuai, $30 \%$ cukup sesuai, 13,3 $\%$ tidak sesuai, $16,7 \%$ sesuai, dan hanya 3,3 \% yang sangat sesuai.

\section{Tabel 4}

\section{Dengan strategi pembelajaran active knowledge sharing saya menjadi sering memberikan kritik dan saran pada setiap kegiatan diskusi}

\begin{tabular}{|c|l|c|c|}
\hline No. & \multicolumn{1}{|c|}{ Alternatif Jawaban } & Frekuensi & Persentase \\
\hline 4 & a. Sangat sesuai & 7 & $23,3 \%$ \\
& b. Sesuai & 1 & $3,3 \%$ \\
& c. Cukup Sesuai & 14 & $46,7 \%$ \\
& d. Tidak sesuai & 5 & $16,7 \%$ \\
& e. Sangat tidak sesuai & 3 & $10 \%$ \\
\hline & \multicolumn{1}{|c|}{ Jumlah } & 30 & $100 \%$ \\
\hline
\end{tabular}

Dari tabel di atas dapat diketahui bahwa mahasiswa PAI STAI ALHIKMAH Jakarta sebagian besar memilih opsi cukup sesuai 
pada pernyataan mengenai kritik dan saran. Hal ini dibuktikan dengan perolehan presentase sebesar $46,7 \%$ cukup sesuai, 23,3 \% sangat sesuai, 3,3\% sesuai, $16,7 \%$ tidak sesuai, dan $10 \%$ sangat tidak sesuai.

\section{Tabel 5}

Saya takut memberi kritik dan saran pada makalah yang telah dibuat kelompok yang sedang presentasi karena sayapun belum sempurna dalam membuat makalah

\begin{tabular}{|c|l|c|c|}
\hline No. & \multicolumn{1}{|c|}{ Alternatif Jawaban } & Frekuensi & Persentase \\
\hline 5 & a. Sangat sesuai & 9 & $30 \%$ \\
& b. Sesuai & 4 & $13,3 \%$ \\
& c. Cukup Sesuai & 5 & $16,7 \%$ \\
& d. Tidak sesuai & 10 & $33,3 \%$ \\
& e. Sangat tidak sesuai & 2 & $6,7 \%$ \\
\hline & \multicolumn{1}{|c|}{ Jumlah } & 30 & $100 \%$ \\
\hline
\end{tabular}

Dari tabel di atas dapat diketahui bahwa mahasiswa PAI STAI ALHIKMAH Jakarta memiliki jawaban yang bervariasi untuk pernyataan ini. Ada beberapa mahasiswa yang merasa sesuai dan juga tidak sesuai. Hal ini dibuktikan dengan perolehan presentase $30 \%$ sangat sesuai, 13,3 \% sesuai, $16,7 \%$ cukup sesuai, 33,3 \% tidak sesuai, dan 6,7\% sangat tidak sesuai.

\section{Tabel 6}

Saya senang memberikan kritik dan saran pada kelompok yang sedang presentasi agar nilai yang mereka dapat dari dosen tidak memuaskan

\begin{tabular}{|c|l|c|c|}
\hline No. & \multicolumn{1}{|c|}{ Alternatif Jawaban } & Frekuensi & Persentase \\
\hline 6 & a. Sangat sesuai & 3 & $10 \%$ \\
& b. Sesuai & 4 & $13,3 \%$ \\
& c. Cukup Sesuai & 1 & $3,3 \%$ \\
& d. Tidak sesuai & 0 & $0 \%$ \\
& e. Sangat tidak sesuai & 22 & $73,3 \%$ \\
\hline & \multicolumn{1}{|c|}{ Jumlah } & 30 & $100 \%$ \\
\hline
\end{tabular}

Dari tabel di atas dapat diketahui bahwa mahasiswa PAI 
STAI ALHIKMAH Jakarta sebagian besar sangat tidak setuju pada pernyataan tersebut. Hal ini dibuktikan dengan perolehan presentase sebesar $73,3 \%$ sangat tidak sesuai, $10 \%$ sesuai, $13,3 \%$ sesuai, dan $3,3 \%$ cukup sesuai.

\section{Tabel 7}

\section{Saya dapat menjelaskan materi yang sedang dibahas dengan detail}

\begin{tabular}{|c|l|c|c|}
\hline No. & \multicolumn{1}{|c|}{ Alternatif Jawaban } & Frekuensi & Persentase \\
\hline 7 & a. Sangat sesuai & 9 & $30 \%$ \\
& b. Sesuai & 10 & $33,3 \%$ \\
& c. Cukup Sesuai & 4 & $13,3 \%$ \\
& d. Tidak sesuai & 5 & $16,7 \%$ \\
& e. Sangat tidak sesuai & 2 & $6,7 \%$ \\
\hline & \multicolumn{1}{|c|}{ Jumlah } & 30 & $100 \%$ \\
\hline
\end{tabular}

Dari tabel di atas dapat diketahui bahwa mahasiswa PAI STAI ALHIKMAH Jakarta memiliki kemampuan yang berbeda-beda dalam menjelaskan materi yang dibahas. Hal ini dibuktikan dengan perolehan presentase sebesar $30 \%$ sangat sesuai, 33,3 \% sesuai, $13,3 \%$ cukup sesuai, $16,7 \%$ tidak sesuai, dan $6,7 \%$ sangat tidak sesuai.

\section{Tabel 8}

\section{Saya membagikan pengetahuan tentang materi yang dibahas sesuai pengalaman}

\begin{tabular}{|c|l|c|c|}
\hline No. & \multicolumn{1}{|c|}{ Alternatif Jawaban } & Frekuensi & Persentase \\
\hline 8 & a. Sangat sesuai & 10 & $33,3 \%$ \\
& b. Sesuai & 10 & $33,3 \%$ \\
& c. Cukup Sesuai & 4 & $13,3 \%$ \\
& d. Tidak sesuai & 5 & $16,7 \%$ \\
& e. Sangat tidak sesuai & 1 & $3,3 \%$ \\
\hline & \multicolumn{1}{|c|}{ Jumlah } & 30 & $100 \%$ \\
\hline
\end{tabular}

Dari tabel di atas dapat diketahui bahwa mahasiswa PAI STAI ALHIKMAH Jakarta sebagian besar membagikan pengetahuan tentang materi yang dibahas sesuai pengalaman. Hal ini dibuktikan 
dengan perolehan presentase sebesar 33,3\% untuk alternative jawaban sangat sesuai dan sesuai, 13,3\% cukup sesuai, 16,7\% tidak sesuai, dan hanya 3,3\% yang sangat tidak sesuai.

\section{Tabel 9}

\section{Saya dapat memahami materi, tetapi sulit untuk menjelaskan kembali}

\begin{tabular}{|c|l|c|c|}
\hline No. & \multicolumn{1}{|c|}{ Alternatif Jawaban } & Frekuensi & Persentase \\
\hline 9 & a. Sangat sesuai & 26 & $86,7 \%$ \\
& b. Sesuai & 1 & $3,3 \%$ \\
& c. Cukup Sesuai & 1 & $3,3 \%$ \\
& d. Tidak sesuai & 1 & $3,3 \%$ \\
& e. Sangat tidak sesuai & 1 & $3,3 \%$ \\
\hline & \multicolumn{1}{|c|}{ Jumlah } & 30 & $100 \%$ \\
\hline
\end{tabular}

Dari tabel di atas dapat diketahui bahwa mahasiswa PAI STAI ALHIKMAH Jakarta sebagian besar merasa sangat sesuai dengan pernyataan. Hal ini dibuktikan dengan perolehan presentase sebesar 86,7 \% sangat sesuai, dan masing-masing 3,3 \% untuk alternative jawaban sesuai, cukup sesuai, tidak sesuai, dan sangat tidak sesuai.

\section{Tabel 10}

\section{Saya selalu memberi contoh nyata setiap menjawab pertanyaan audiens}

\begin{tabular}{|c|l|c|c|}
\hline No. & \multicolumn{1}{|c|}{ Alternatif Jawaban } & Frekuensi & Persentase \\
\hline 10 & a. Sangat sesuai & 2 & $6,7 \%$ \\
& b. Sesuai & 16 & $53,3 \%$ \\
& c. Cukup Sesuai & 5 & $16,7 \%$ \\
& d. Tidak sesuai & 5 & $16,7 \%$ \\
& e. Sangat tidak sesuai & 2 & $6,7 \%$ \\
\hline & \multicolumn{1}{|c|}{ Jumlah } & 30 & $100 \%$ \\
\hline
\end{tabular}

Dari tabel di atas dapat diketahui bahwa mahasiswa PAI STAI ALHIKMAH Jakarta sebagian besar selalu memberi contoh nyata setiap menjawab pertanyaan audiens. Hal ini dibuktikan denga perolehan presentase sebesar $53,3 \%$ sesuai, $16,7 \%$ cukup dan tidak sesuai, $6,7 \%$ sesuai dan sangat tidak sesuai. 


\section{Tabel 11}

Saya jarang menemukan contoh nyata untuk memperkuat jawaban dalam diskusi

\begin{tabular}{|c|l|c|c|}
\hline No. & \multicolumn{1}{|c|}{ Alternatif Jawaban } & Frekuensi & Persentase \\
\hline 11 & a. Sangat sesuai & 2 & $6,7 \%$ \\
& b. Sesuai & 6 & $20 \%$ \\
& c. Cukup Sesuai & 8 & $26,7 \%$ \\
& d. Tidak sesuai & 10 & $33,3 \%$ \\
& e. Sangat tidak sesuai & 4 & $13,3 \%$ \\
\hline & \multicolumn{1}{|c|}{ Jumlah } & 30 & $100 \%$ \\
\hline
\end{tabular}

Dari tabel di atas dapat diketahui bahwa mahasiswa PAI STAI ALHIKMAH Jakarta memiliki pengalaman yang berbeda terkait pernyataan ini. Hal ini dibuktikan dengan perolehan presentase sebesar $6,7 \%$ sangat sesuai, $20 \%$ sesuai, $26,7 \%$ cukup sesuai, 33,3 $\%$ tidak sesuai, dan $13,3 \%$ sangat tidak sesuai.

\section{Tabel 12}

\section{Saya selalu bertanya pada saat diskusi mengenai materi yang sedang dibahas}

\begin{tabular}{|c|l|c|c|}
\hline No. & \multicolumn{1}{|c|}{ Alternatif Jawaban } & Frekuensi & Persentase \\
\hline 12 & a. Sangat sesuai & 6 & $20 \%$ \\
& b. Sesuai & 14 & $46,7 \%$ \\
& c. Cukup Sesuai & 3 & $10 \%$ \\
& d. Tidak sesuai & 5 & $16,7 \%$ \\
& e. Sangat tidak sesuai & 2 & $6,6 \%$ \\
\hline & \multicolumn{1}{|c|}{ Jumlah } & 30 & $100 \%$ \\
\hline
\end{tabular}

Dari tabel di atas dapat diketahui bahwa mahasiswa PAI STAI ALHIKMAH Jakarta memiliki pengalaman yang sesuai dengan pernyataan. Hal ini dibuktikan dengan perolehan presentase sebesar $46,7 \%$ sesuai, $20 \%$ sangat sesuai, $10 \%$ cukup sesuai, 16,7 $\%$ tidak sesuai, dan $6,6 \%$ sangat tidak sesuai. 


\section{Tabel 13}

\section{Saya lebih memilih untuk mencari jawaban sendiri di internet dibandingkan harus bertanya}

\begin{tabular}{|c|l|c|c|}
\hline No. & \multicolumn{1}{|c|}{ Alternatif Jawaban } & Frekuensi & Persentase \\
\hline 13 & a. Sangat sesuai & 1 & $3,3 \%$ \\
& b. Sesuai & 4 & $13,3 \%$ \\
& c. Cukup Sesuai & 2 & $6,7 \%$ \\
& d. Tidak sesuai & 23 & $76,7 \%$ \\
& e. Sangat tidak sesuai & 0 & $0 \%$ \\
\hline & \multicolumn{1}{|c|}{ Jumlah } & 30 & $100 \%$ \\
\hline
\end{tabular}

Dari tabel di atas dapat diketahui bahwa mahasiswa PAI STAI ALHIKMAH Jakarta memiliki pengalaman yang tidak sesuai dengan pernyataan. Hal ini dibuktikan dengan perolehan presentase sebesar 76,7 \% tidak sesuai, 3,3 \% sangat sesuai, 13,3\% sesuai, dan $6,7 \%$ cukup sesuai.

\section{Tabel 14}

Saya sering menyanggah jawaban dari pemakalah agar diskusi semakin seru

\begin{tabular}{|c|l|c|c|}
\hline No. & \multicolumn{1}{|c|}{ Alternatif Jawaban } & Frekuensi & Persentase \\
\hline 14 & a. Sangat sesuai & 2 & $7 \%$ \\
& b. Sesuai & 5 & $17 \%$ \\
& c. Cukup Sesuai & 6 & $20 \%$ \\
& d. Tidak sesuai & 11 & $39 \%$ \\
& e. Sangat tidak sesuai & 6 & $17 \%$ \\
\hline & \multicolumn{1}{|c|}{ Jumlah } & 30 & $100 \%$ \\
\hline
\end{tabular}

Dari tabel di atas dapat diketahui bahwa mahasiswa PAI STAI ALHIKMAH Jakarta sebagian besar memiliki pengalaman yang tidak sesuai dengan pernyataan. Hal ini dibuktikan dengan perolehan presentase sebesar $39 \%$ tidak sesuai, $17 \%$ sangat tidak sesuai, $20 \%$ cukup sesuai, $17 \%$ sesuai, dan $7 \%$ sangat sesuai. 


\section{Tabel 15}

Saya senang menambahkan jawaban pemakalah dan audiens agar jawaban yang didapat penanya lebih lengkap

\begin{tabular}{|c|l|c|c|}
\hline No. & \multicolumn{1}{|c|}{ Alternatif Jawaban } & Frekuensi & Persentase \\
\hline 15 & a. Sangat sesuai & 4 & $13,3 \%$ \\
& b. Sesuai & 19 & $63,3 \%$ \\
& c. Cukup Sesuai & 3 & $10 \%$ \\
& d. Tidak sesuai & 2 & $6,7 \%$ \\
& e. Sangat tidak sesuai & 2 & $6,7 \%$ \\
\hline & \multicolumn{1}{|c|}{ Jumlah } & 30 & $100 \%$ \\
\hline
\end{tabular}

Dari tabel di atas dapat diketahui bahwa mahasiswa PAI STAI ALHIKMAH Jakarta sebagian besar senang menambahkan jawaban pemakalah dan audiens agar jawaban yang didapat penanya lebih lengkap. Hal ini dibuktikan dengan perolehan skor sebesar 63,3 \% sesuai, 13,3 \% sangat sesuai, $10 \%$ cukup sesuai, sedangkan yang tidak sesuai dan yang sangat tidak sesuai hanya $6,7 \%$ dari keseluruhan mahasiswa.

Adapun perhitungan frekuensi dan presentase dari setiap pernyataan untuk variable motivasi belajar (variabel Y) sebagai berikut :

\section{Tabel 16}

\section{Saya selalu hadir pada jam matakuliah masa'ilul fiqhiyah}

\begin{tabular}{|c|l|c|c|}
\hline No. & \multicolumn{1}{|c|}{ Alternatif Jawaban } & Frekuensi & Persentase \\
\hline 1 & a. Sangat sesuai & 13 & $43,3 \%$ \\
& b. Sesuai & 6 & $20 \%$ \\
& c. Cukup Sesuai & 4 & $13,3 \%$ \\
& d. Tidak sesuai & 5 & $16,7 \%$ \\
& e. Sangat tidak sesuai & 2 & $6,7 \%$ \\
\hline & \multicolumn{1}{|c|}{ Jumlah } & 30 & $100 \%$ \\
\hline
\end{tabular}

Dari tabel di atas dapat diketahui bahwa mahasiswa PAI STAI ALHIKMAH Jakarta sebagian besar selalu hadir pada jam matakuliah masa'ilul fiqhiyah. Hal ini dibuktikan dengan perolehan presentase sebesar 43,3\% sangat sesuai, $20 \%$ sesuai, 13,3 \% cukup sesuai, $16,7 \%$ tidak sesuai, dan $6,7 \%$ sangat tidak sesuai. 


\section{Tabel 17}

\section{Saya mengikuti KBM dari awal hingga akhir}

\begin{tabular}{|c|l|c|c|}
\hline No. & \multicolumn{1}{|c|}{ Alternatif Jawaban } & Frekuensi & Persentase \\
\hline 2 & a. Sangat sesuai & 4 & $13,3 \%$ \\
& b. Sesuai & 4 & $13,3 \%$ \\
& c. Cukup Sesuai & 13 & $43,3 \%$ \\
& d. Tidak sesuai & 7 & $23,3 \%$ \\
& e. Sangat tidak sesuai & 2 & $6,8 \%$ \\
\hline & \multicolumn{1}{|c|}{ Jumlah } & 30 & $100 \%$ \\
\hline
\end{tabular}

Dari tabel di atas dapat diketahui bahwa mahasiswa PAI STAI ALHIKMAH Jakarta sebagian besar memiliki kebiasaan yang cukup sesuai dengan pernyataan. Hal ini dibuktikan dengan perolehan presentase sebesar 43,3\% cukup sesuai, 13,3\% untuk alternative jawaban sangat sesuai dan sesuai, 23,3\% tidak sesuai, dan 6,8 \% sangat tidak sesuai.

\section{Tabel 18}

\section{Saya hanya focus belajar pada pembahasan yang disukai}

\begin{tabular}{|c|l|c|c|}
\hline No. & \multicolumn{1}{|c|}{ Alternatif Jawaban } & Frekuensi & Persentase \\
\hline 3 & a. Sangat sesuai & 1 & $3,3 \%$ \\
& b. Sesuai & 6 & $20 \%$ \\
& c. Cukup Sesuai & 9 & $30 \%$ \\
& d. Tidak sesuai & 8 & $26,7 \%$ \\
& e. Sangat tidak sesuai & 6 & $20 \%$ \\
\hline & \multicolumn{1}{|c|}{ Jumlah } & 30 & $100 \%$ \\
\hline
\end{tabular}

Dari tabel di atas dapat diketahui bahwa mahasiswa PAI STAI ALHIKMAH Jakarta memiliki kebiasaan yang berbeda terkait dengan pernyataan ini. Hal ini dibuktikan dengan perolehan presentase dari yang terbesar yaitu $30 \%$ untuk pernyataan cukup sesuai, $26,7 \%$ tidak sesuai, $20 \%$ sesuai dan tidak sesuai, dan 3,3\% sangat sesuai. 


\section{Tabel 19}

Saya merasa tertantang untuk menyelesaikan jika materi yang diberikan dosen sulit

\begin{tabular}{|c|l|c|c|}
\hline No. & \multicolumn{1}{|c|}{ Alternatif Jawaban } & Frekuensi & Persentase \\
\hline 4 & a. Sangat sesuai & 7 & $23,3 \%$ \\
& b. Sesuai & 4 & $13,3 \%$ \\
& c. Cukup Sesuai & 9 & $30 \%$ \\
& d. Tidak sesuai & 5 & $16,7 \%$ \\
& e. Sangat tidak sesuai & 5 & $16,7 \%$ \\
\hline & \multicolumn{1}{|c|}{ Jumlah } & 30 & $100 \%$ \\
\hline
\end{tabular}

Dari tabel di atas dapat diketahui bahwa mahasiswa PAI STAI ALHIKMAH Jakarta sebagian besar menyatakan cukup tertantang untuk menyelesaikan materi yang sulit dari dosen. $\mathrm{Hal}$ ini dibuktikan dengan perolehan presentase sebesar $30 \%$ cukup sesuai, kemudian 23,3\% sangat sesuai, 16,7 \% tidak sesuai dan sangat sesuai, kemudian $13,3 \%$ sesuai.

\section{Tabel 20}

\section{Saya akan mengabaikan pelajaran jika pembahasannya sulit dimengerti}

\begin{tabular}{|c|l|c|c|}
\hline No. & \multicolumn{1}{|c|}{ Alternatif Jawaban } & Frekuensi & Persentase \\
\hline 5 & a. Sangat sesuai & 7 & $23,3 \%$ \\
& b. Sesuai & 4 & $13,3 \%$ \\
& c. Cukup Sesuai & 8 & $26,7 \%$ \\
& d. Tidak sesuai & 8 & $26,7 \%$ \\
& e. Sangat tidak sesuai & 3 & $10 \%$ \\
\hline & \multicolumn{1}{|c|}{ Jumlah } & 30 & $100 \%$ \\
\hline
\end{tabular}

Dari tabel di atas dapat diketahui bahwa mahasiswa PAI STAI ALHIKMAH Jakarta memiliki kebiasaan yang berbeda dalam menanggapi pelajaran. Hal ini di dibuktikan dengan perolehan presentase sebesar 23,3 \% sangat sesuai, 13,3\% sesuai, 26,7 \% cukup dan tidak sesuai, kemudian sebesar $10 \%$ sangat tidak sesuai. 


\section{Tabel 21}

Jika materinya sulit saya akan menunggu teman saya menanyakannya pada dosen

\begin{tabular}{|c|l|c|c|}
\hline No. & \multicolumn{1}{|c|}{ Alternatif Jawaban } & Frekuensi & Persentase \\
\hline 6 & a. Sangat sesuai & 0 & $0 \%$ \\
& b. Sesuai & 10 & $33,3 \%$ \\
& c. Cukup Sesuai & 9 & $30 \%$ \\
& d. Tidak sesuai & 7 & $23,3 \%$ \\
& e. Sangat tidak sesuai & 4 & $13,4 \%$ \\
\hline & \multicolumn{1}{|c|}{ Jumlah } & 30 & $100 \%$ \\
\hline
\end{tabular}

Dari tabel di atas dapat diketahui bahwa mahasiswa PAI STAI ALHIKMAH Jakarta memiliki jawaban yang berbeda pada pernyataan ini. Namun dari pernyataan tersebut tidak ada yang menjawab sangat sesuai terhadap pernyataan. Hal ini dibuktikan dengan perolehan presentase sebesar $0 \%$ untuk sangat sesuai, 33,3 $\%$ sesuai, 30 \% cukup sesuai, 23,3 \% tidak sesuai, dan 13,4 \% sangat tidak sesuai.

\section{Tabel 22}

Saya bermain hp pada saat jam pelajaran

\begin{tabular}{|c|l|c|c|}
\hline No. & \multicolumn{1}{|c|}{ Alternatif Jawaban } & Frekuensi & Persentase \\
\hline 7 & a. Sangat sesuai & 5 & $16,7 \%$ \\
& b. Sesuai & 8 & $26,7 \%$ \\
& c. Cukup Sesuai & 5 & $16,7 \%$ \\
& d. Tidak sesuai & 2 & $6,7 \%$ \\
& e. Sangat tidak sesuai & 10 & $33,2 \%$ \\
\hline & \multicolumn{1}{|c|}{ Jumlah } & 30 & $100 \%$ \\
\hline
\end{tabular}

Dari tabel di atas dapat diketahui bahwa mahasiswa PAI STAI ALHIKMAH Jakarta memiliki jawaban yang berbeda dalam menggunakan hp pada saat jam pelajaran. Hal ini dibuktikan dengan perolehan presentase $16,7 \%$ sangat sesuai, $26,7 \%$ sesuai, $16,7 \%$ cukup sesuai, $6,7 \%$ tidak sesuai, dan 33,2 \% sangat tidak sesuai. 


\section{Tabel 23}

\section{Saya memperhatikan dengan baik pembahasan yang diajarkan dosen}

\begin{tabular}{|c|l|c|c|}
\hline No. & \multicolumn{1}{|c|}{ Alternatif Jawaban } & Frekuensi & Persentase \\
\hline 8 & a. Sangat sesuai & 1 & $3,3 \%$ \\
& b. Sesuai & 5 & $16,7 \%$ \\
& c. Cukup Sesuai & 9 & $30 \%$ \\
& d. Tidak sesuai & 6 & $20 \%$ \\
& e. Sangat tidak sesuai & 9 & $30 \%$ \\
\hline & \multicolumn{1}{|c|}{ Jumlah } & 30 & $100 \%$ \\
\hline
\end{tabular}

Dari tabel di atas dapat diketahui bahwa mahasiswa PAI STAI ALHIKMAH Jakarta memiliki jawaban yang rata-rata kurang sesuai dengan pernyataan. Hal ini ditunjukan dengan perolehan presentase sebesar $30 \%$ untuk pernyataan cukup dan sangat tidak sesuai, $20 \%$ tidak sesuai, 16,7 \% sesuai, dan 3,3\% sangat sesuai.

\section{Tabel 24}

\section{Saya perlu mempelajari pembahasan matakuliah masa'ilul} fiqhiyah karena akan berhubungan dengan kegiatan seharihari

\begin{tabular}{|c|l|c|c|}
\hline No. & \multicolumn{1}{|c|}{ Alternatif Jawaban } & Frekuensi & Persentase \\
\hline 9 & a. Sangat sesuai & 4 & $13,3 \%$ \\
& b. Sesuai & 7 & $23,3 \%$ \\
& c. Cukup Sesuai & 10 & $33,4 \%$ \\
& d. Tidak sesuai & 9 & $30 \%$ \\
& e. Sangat tidak sesuai & 0 & $0 \%$ \\
\hline & \multicolumn{1}{|c|}{ Jumlah } & 30 & $100 \%$ \\
\hline
\end{tabular}

Dari tabel di atas dapat diketahui bahwa mahasiswa PAI STAI ALHIKMAH Jakarta tidak ada mahasiswa yang sangat tidak sesuai dengan pernyataan. Hal ini dibuktikan dengan perolehan presentase $0 \%$ untuk sangat tidak sesuai, sedangkan alternative jawaban yang lain 13,3\% sangat sesuai, 23,3 \% sesuai, 33,4 \% tidak sesuai, dan $30 \%$ tidak sesuai. 


\section{Tabel 25}

Saya harus bisa memahami setiap materi yang dibahas pada matakuliah masa'ilul fiqhiyah agar selalu mendapat nilai yang memuaskan

\begin{tabular}{|c|l|c|c|}
\hline No. & \multicolumn{1}{|c|}{ Alternatif Jawaban } & Frekuensi & Persentase \\
\hline 10 & a. Sangat sesuai & 4 & $13,3 \%$ \\
& b. Sesuai & 6 & $20 \%$ \\
& c. Cukup Sesuai & 12 & $40 \%$ \\
& d. Tidak sesuai & 7 & $23,4 \%$ \\
& e. Sangat tidak sesuai & 1 & $3,3 \%$ \\
\hline & \multicolumn{1}{|c|}{ Jumlah } & 30 & $100 \%$ \\
\hline
\end{tabular}

Dari tabel di atas dapat diketahui bahwa mahasiswa PAI STAI ALHIKMAH Jakarta sebagian besar menjawab cukup sesuai dengan pernyataan. Hal ini dibuktikan dengan perolehan presentase sebesar $40 \%$, cukup sesuai, kemudian 23,4\% tidak sesuai, $20 \%$ sesuai, $13,3 \%$ sangat sesuai, dan 3,3 \% sangat tidak sesuai.

\section{Tabel 26}

Saya tidak terlalu menginginkan nilai yang tinggi

\begin{tabular}{|c|l|c|c|}
\hline No. & \multicolumn{1}{|c|}{ Alternatif Jawaban } & Frekuensi & Persentase \\
\hline 11 & a. Sangat sesuai & 5 & $16,7 \%$ \\
& b. Sesuai & 10 & $33,3 \%$ \\
& c. Cukup Sesuai & 7 & $23,3 \%$ \\
& d. Tidak sesuai & 6 & $20 \%$ \\
& e. Sangat tidak sesuai & 2 & $6,7 \%$ \\
\hline & \multicolumn{1}{|c|}{ Jumlah } & 30 & $100 \%$ \\
\hline
\end{tabular}

Dari tabel di atas dapat diketahui bahwa mahasiswa PAI STAI ALHIKMAH Jakarta sebagian besar menjawab sesuai dengan pernyataan. Hal ini dibuktikan dengan perolehan presentase sebesar 33,3 \% sesuai, kemudian 23,3\% cukup sesuai, $20 \%$ tidak sesuai, $16,7 \%$ sangat sesuai, dan $6,7 \%$ sangat tidak sesuai. tidak sesuai. 


\section{Tabel 27}

Saya tidak mempunyai target dalam mencapai hasil belajar

\begin{tabular}{|c|l|c|c|}
\hline No. & \multicolumn{1}{|c|}{ Alternatif Jawaban } & Frekuensi & Persentase \\
\hline 12 & a. Sangat sesuai & 1 & $3,3 \%$ \\
& b. Sesuai & 4 & $13,3 \%$ \\
& c. Cukup Sesuai & 5 & $16,7 \%$ \\
& d. Tidak sesuai & 14 & $46,7 \%$ \\
& e. Sangat tidak sesuai & 6 & $20 \%$ \\
\hline & \multicolumn{1}{|c|}{ Jumlah } & 30 & $100 \%$ \\
\hline
\end{tabular}

Dari tabel di atas dapat diketahui bahwa mahasiswa PAI STAI ALHIKMAH Jakarta sebagian besar menjawab tidak sesuai dengan pernyataan. Hal ini dibuktikan dengan perolehan presentase sebesar 46,7 \% sangat tidak sesuai, kemudian $20 \%$ sangat tidak sesuai, $16,7 \%$ cukup sesuai, 13,3 \% sesuai, dan 3,3\% sangat sesuai.

\section{Tabel 28}

\section{Saya dapat menyelesaikan tugas dengan usaha sendiri}

\begin{tabular}{|c|l|c|c|}
\hline No. & \multicolumn{1}{|c|}{ Alternatif Jawaban } & Frekuensi & Persentase \\
\hline 13 & a. Sangat sesuai & 0 & $0 \%$ \\
& b. Sesuai & 8 & $26,7 \%$ \\
& c. Cukup Sesuai & 14 & $46,6 \%$ \\
& d. Tidak sesuai & 5 & $16,7 \%$ \\
& e. Sangat tidak sesuai & 3 & $10 \%$ \\
\hline & \multicolumn{1}{|c|}{ Jumlah } & 30 & $100 \%$ \\
\hline
\end{tabular}

Dari tabel di atas dapat diketahui bahwa mahasiswa PAI STAI ALHIKMAH Jakarta sebagian besar menjawab cukup sesuai dengan pernyataan. Hal ini dibuktikan dengan perolehan presentase sebesar 46,6 \%, selanjutnya jawaban sesuai $26,7 \%$, tidak sesuai $16,7 \%$, dan sangat tidak sesuai $10 \%$. 


\section{Tabel 29}

\section{Saya lebih senang pergi ke kantin pada saat jam pelajaran kosong}

\begin{tabular}{|c|l|c|c|}
\hline No. & \multicolumn{1}{|c|}{ Alternatif Jawaban } & Frekuensi & Persentase \\
\hline 14 & a. Sangat sesuai & 2 & $6,7 \%$ \\
& b. Sesuai & 4 & $13,3 \%$ \\
& c. Cukup Sesuai & 20 & $66,7 \%$ \\
& d. Tidak sesuai & 4 & $13,3 \%$ \\
& e. Sangat tidak sesuai & 0 & $10 \%$ \\
\hline & \multicolumn{1}{|c|}{ Jumlah } & 30 & $100 \%$ \\
\hline
\end{tabular}

Dari tabel di atas dapat diketahui bahwa mahasiswa PAI STAI ALHIKMAH Jakarta sebagian besar menjawab cukup sesuai dengan pernyataan. Hal ini dibuktikan dengan perolehan terbanyak sebesar $66,7 \%$, kemudian 13,3 \% untuk jawaban sesuai dan tidak sesuai, dan $6,7 \%$ untuk jawaban sangat tidak sesuai.

\section{Tabel 30}

\section{Saya sering berkunjung ke perpustakaan untuk membaca kembali materi yang telah dibahas}

\begin{tabular}{|c|l|c|c|}
\hline No. & \multicolumn{1}{|c|}{ Alternatif Jawaban } & Frekuensi & Persentase \\
\hline 15 & a. Sangat sesuai & 5 & $16,7 \%$ \\
& b. Sesuai & 7 & $23,3 \%$ \\
& c. Cukup Sesuai & 7 & $23,3 \%$ \\
& d. Tidak sesuai & 8 & $26,7 \%$ \\
& e. Sangat tidak sesuai & 3 & $10 \%$ \\
\hline & \multicolumn{1}{|c|}{ Jumlah } & 30 & $100 \%$ \\
\hline
\end{tabular}

Dari tabel di atas dapat diketahui bahwa mahasiswa PAI STAI ALHIKMAH Jakarta memiliki kebiasaan yang berbeda dalam berkunjung ke perpustakaan. Hal ini dibuktikan dengan perolehan presentase terbanyak sebesar $26,7 \%$ untuk jawaban tidak sesuai, 23,3 untuk sesuai dan cukup sesuai, 16,7 \% sangat sesuai, dan 10 $\%$ sangat tidak sesuai.

Penelitian yang dilakukan di STAI ALHIKMAH Jakarta kepada mahasiswa PAI angkatan 2015 menghasilkan beberapa temuan, 
yakni dalam pengujian instrument penelitian, semula angket berjumlah 15 item pernyataan variable strategi pembelajaran active knowledge sharing dan 15 item pernyataan variable motivasi belajar, setelah disajikan kepada 30 mahasiswa maka diketahui bahwa seluruh pernyataan dianggap valid. Instrumen ini juga dianggap reliable, sebab reliabilitas strategi pembelajaran active knowledge sharing dengan 15 item yang valid diperoleh 0,942 dan reliabilitas motivasi belajar dengan 15 item yang valid diperoleh 0,944. Instrumen berupa angket ini diujikan kepada 30 mahasiswa.

Pada analisa deskriptif diketahui bahwa sampel penelitian adalah terdiri dari 16 mahasiswa dan 14 mahasiswi sehingga total valid pada sampel adalah 30 sampel.

Dari uji korelasi ditemukan bahwa nilai $r$ hitung lebih besar dari $r$ tabel $(0,871>0,361)$ sehingga Ha diterima dan Ho ditolak. Dan artinya terdapat hubungan yang sangat kuat antara strategi pembelajaran active knowledge sharing terhadap motivasi belajar matakuliah masa'ilul fiqhiyah mahasiswa PAI angkatan 2015 STAI ALHIKMAH Jakarta.

Dalam uji regresi dinyatakan bahwa nilai koefisien korelasi ( $r$ ) adalah 0,871 yang artinya korelasi antar kedua variable terbilang sangat kuat karena berada pada rentang 0,80 - 1,00. Dan korelasi determinasi (r2) yang didapat adalah sebesar 0,758. Hal ini berarti bahwa variable strategi pembelajaran active knowledge sharing memberikan sumbangsih pengaruh sebesar $75,8 \%$ bagi perubahan variable motivasi belajar matakuliah masa'ilul fiqhiyah mahasiswa PAI angkatan 2015 STAI ALHIKMAH Jakarta.

Berdasarkan hasil perhitungan di atas nilai t hitung 9,364 $\geq \mathrm{t}$ tabel $\geq 1,697$ maka Ho ditolak yang artinya $t$ hitung $\geq \mathrm{t}$ tabel dan dapat kita ketahui bahwa Ha yang diterima dan Ho ditolak.

\section{E. PEMBAHASAN TEMUAN PENELITIAN}

Berdasarkan hasil pengamatan yang dilakukan dapat dinyatakan bahwa motivasi belajar mahasiswa bergantung pada 
strategi pembelajaran yang digunakan. Di kelas PAI Semester VII A angkatan 2015 terdapat mahasiswa yang aktif saat pembelajaran dan ada juga yang pasif. Dalam hal ini yang perlu ditingkatkan adalah membuat gaya komunikasi dalam proses pembelajaran lebih variatif dan tidak monoton pada satu strategi. Dosen yang hanya puas dengan satu strategi pembelajaran menggambarkan ketidak mampuan dalam mengkomunikasikan tugasnya. Selain itu kenyataan dari hasil observasi bahwa jika dosen tidak mampu menampilkan variasi pembelajaran konsekuensinya akan membuat mahasiswa jenuh dan bosan. Karena dalam pembelajaran yang diberikan kepada siswa harus dilakukan dengan berbagai bentuk seperti daftar pertanyaan mengenai suatu pokok bahasan tertentu, suatu perintah yang dibahas melalui diskusi atau perlu dicari uraiannya dalam buku pelajaran yang lain. Dan semuanya itu bertujuan untuk meningkatkan efektifitas dan efisiensi proses belajar mengajar

Dosen yang diteliti sangat baik dalam memberi penilaian, hal ini mengacu pada keaktifan mahasiswa dan tugas makalah yang dipresentasikan. Evaluasi menjadi pokok utama dalam pengkomunikasian, dimana setelah mahasiswa menyelesaikan diskusi mengenai pembahasan, dosen akan membahas kembali dan meluruskan jawaban masing-masing mahasiswa dengan lebih jelas. Kemampuan dosen dalam mengkomunikasi tugas jelas, sesuai dengan nalar mahasiswa, dan kemampuan dalam mengevaluasi serta memberikan penilaian mampu meningkatkan pemahaman mahasiswa terhadap materi yang diberikan. Pengamatan dalam observasi menggambarkan pentingnya strategi pembelajaran dan motivasi dalam sebuah pembelajaran.

Berdasarkan data yang diperoleh dari hasil analisis yang dilakukan terdapat pengaruh yang signifikan antara strategi pembelajaran active knowledge sharing terhadap motivasi belajar matakuliah masa'ilul fiqhiyah mahasiswa PAI angkatan 2015 STAI ALHIKMAH Jakarta. Hal ini dibuktikan dengan perolehan $r$ hitung $>\mathrm{r}$ tabel $(0,871>0,361)$ yang berarti Ha diterima dan Ho ditolak. Dan besarnya pengaruh strategi pembelajaran active knowledge 
sharing terhadap motivasi belajar matakuliah masa'ilul fiqhiyah mahasiswa PAI angkatan 2015 STAI ALHIKMAH Jakarta sebesar $75,8 \%$, sedangkan $24,2 \%$ motivasi belajar dipengaruhi variable lain yang tidak diteliti.

Dari hasil penelitian ini dapat dimanfaatkan sebagai alat analisa perkembangan motivasi belajar mahasiswa, dan dapat dijadikan sebagai data acuan untuk program pembinaan. Para mahasiswa hendaknya selalu dapat mengetahui bagaimana usaha yang harus dilakukan sendiri agar motivasi belajarnya pada setiap matakuliah menjadi baik, sehingga saat pembelajaran sedang berlangsung mahasiswa dapat mengikuti dengan aktif tanpa menunggu dosen menggunakan strategi yang dapat meningkatkan motivasi belajar.

Karena motivasi belajar mahasiswa memiliki posisi yang penting dalam setiap pembelajaran, maka seyogyanya dosen dapat lebih memilih dan mempersiapkan strategi yang akan digunakan pada pemberian matakuliah.

\section{F. KESIMPULAN}

Berdasarkan data yang diperoleh dari hasil analisis yang dilakukan maka dapat diambil kesimpulan bahwa terdapat pengaruh yang signifikan antara strategi pembelajaran active knowledge sharing terhadap motivasi belajar matakuliah masa’ilul fiqhiyah mahasiswa PAI angkatan 2015 STAI ALHIKMAH Jakarta. Hal ini dibuktikan dengan perolehan $\mathrm{r}$ hitung > $\mathrm{r}$ tabel $(0,871>$ 0,361 ) yang berarti Ha diterima dan Ho ditolak. Besarnya pengaruh strategi pembelajaran active knowledge sharing terhadap motivasi belajar matakuliah masa'ilul fiqhiyah mahasiswa PAI angkatan 2015 STAI ALHIKMAH Jakarta sebesar 75,8\%, sedangkan 24,2\% motivasi belajar dipengaruhi variable lain yang tidak diteliti.[] 


\section{DAFTAR PUSTAKA}

Abdul Majib, Strategi Pembelajaran, Bandung : Remaja Rosdakarya, 2013.

Abdurrohman Kasdi, Masail Fiqhiyyah, Kudus : Nora Media Enterprise.

Anisah Basleman dan Syamsu Mappa, Teori Belajar Orang Dewasa, Bandung :Remaja Rosdakarya, 2011.

Asri Nafia Dewi, "Pengaruh Penggunaan Model Active Knowledge Sharing terhadap Hasil Belajar Ditinjau dari Minat Belajar Siswa SMA N 2 Karanganyar,"Penelitian disampaikan pada Seminar Nasional IX Pendidikan Biologi, FKIP Universitas Sebelas Maret, Surakarta.

Daniel Muijis dn David Reynolds, Effective Teaching Evidence and Practice, London: SAGE Publication Ltd, 2005.

Desi Purwaningsih, Pengaruh Penggunaan Strategi Pembelajaran Active Knowledge Sharing terhadap Hasil Belajar Biologi, Ditinjau dari Gaya Belajar Siswa Kelas X SMA Negeri 5 Surakarta Tahun Pelajaran 2011/2012, Jurnal Pendidikan, Vol.3 no, September 2011.

Hasyim Zaini, Strategi Pembelajaran Active, Yogyakarta: Pustaka Insan Madani, 2008.

M. Ngalim Purwanto, Psikologi Pendidikan, Bandung : Remaja Rosdakarya, 1998.

Muhibbin Syah, Psikologi Pendidikan dengan Pendekatan Baru, Bandung : Rosdakarya, 2008, Cet ke-14.

Oxford Fajar Sdn. Bhd, Oxford Student's Dictionary of English, Malaysia : Fajar Bakti Sdn. Bhd, 2007.

Pat Hollingsworth dan Gina Lewis, Pembelajaran Aktif: Meningkatkan Keasyikan Kegiatan di Kelas, Jakarta : Indeks, 2008. 
S. Nasution, Didaktif Asas-asas Mengajar, Bandung : Jemmars, 1986.

, Teknologi Pendidikan, Bandung : Bumi Aksara, 1982.

Sardiman A.M, Interaksi dan Motivasi Belajar Mengajar, Jakarta : Raja Grafindo Persada, 2007), h.73

Syaiful Bahri Djamarah, Strategi Belajar Mengajar, Jakarta : Rineka Cipta, 2002.

Teungku Muhammad Hasbi Ash-Shiddieqy, Pengantar Ilmu Fiqih, Semarang : PT. Pustaka Rizki Putra, 1999, Edisi Kedua.

W.S Winnkel, Psikologi Pendidikan dan Evaluasi Belajar, Jakarta :PT. Gramedia, 1983. 